\title{
CP-31398 restores mutant p53 tumor suppressor function and inhibits UVB-induced skin carcinogenesis in mice
}

\author{
Xiuwei Tang, ${ }^{1}$ Yucui Zhu, ${ }^{1}$ Lydia Han, ${ }^{1}$ Arianna L. Kim, ${ }^{1}$ Levy Kopelovich, ${ }^{2}$ \\ David R. Bickers, ${ }^{1}$ and Mohammad Athar ${ }^{1}$ \\ 1Department of Dermatology, Columbia University College of Physicians and Surgeons, New York, New York, USA. 2Division of Cancer Prevention, \\ National Cancer Institute, Bethesda, Maryland, USA.
}

\begin{abstract}
Mutations in the tumor suppressor p53 are detectable in over $50 \%$ of all human malignancies. Mutant p53 protein is incapable of transactivating its downstream target genes that are required for DNA repair and apoptosis. Chronic exposure to UVB induces $p 53$ mutations and is carcinogenic in both murine and human skin. CP-31398, a styrylquinazoline compound, restores the tumor suppressor functions of mutant forms of $\mathrm{p} 53$ in tumor cells. However, its effectiveness in vivo remains unclear. Here, we demonstrate that CP-31398 blocked UVB-induced skin carcinogenesis and was associated with increases in $\mathrm{p} 53, \mathrm{p} 21$, and $\mathrm{BclXs}$. CP-31398 downregulated $\mathrm{Bcl} 2$, proliferating nuclear cell antigen, and cyclin D1. Activation of caspase-3 and cleavage of poly (ADP-ribose) polymerase also occurred in both tumor and perilesional skin following treatment. CP-31398 induced the expression of p53-dependent target proteins, and this was followed by apoptosis in UVB-irradiated wild-type mice but not in their p53-deficient littermates. Similar effects were observed in human skin carcinoma A431 cells expressing mutant p53. In addition, CP-31398 induced mitochondrial translocation of p53, leading to changes in mitochondrial membrane permeability pore transition (MPT) and consequent cytochrome $c$ release in these cells. Blocking MPT diminished p53 translocation and apoptosis. These studies indicate that reconstituting $\mathrm{p} 53$ tumor suppressor functions in vivo by small molecular weight compounds may block the pathogenesis and progression of skin cancer.
\end{abstract}

\section{Introduction}

The tumor suppressor p53 is among the most frequently mutated genes in virtually all human cancers $(1,2)$. It has been estimated that more than $50 \%$ of all human malignancies, including nonmelanoma skin cancers (NMSCs), which include squamous cell carcinomas (SCCs) and basal cell carcinomas, have detectable p53 mutations (http://www-p53.iarc.fr/index.html). The remaining $50 \%$ that retain wild-type p53 often employ alternative mechanisms for its inactivation (2). The typical pathway for the induction of NMSCs is a multistep process involving initiation (mutation), promotion (clonal expansion), and malignant progression, during which additional mutations accumulate, resulting in increasing genetic instability (3). Solar UVB radiation is a wellknown risk factor for the induction and development of NMSCs $(4,5)$. UVB induces mutagenic photoproducts in DNA, which include cyclobutane dimers between adjacent pyrimidines as well as (6-4) photoproducts. Both lesions frequently occur in runs of tandem pyrimidine residues, known as "hot spots" for UVBinduced mutations. Although both photoproducts are potentially mutagenic, cyclobutane dimers are thought to be the major contributors to mammalian mutations in part because (6-4) photoproducts are repaired much more efficiently than are cyclobutane

Nonstandard abbreviations used: mJ, millijoules; MnSOD, manganese superoxide dismutase; MPT, mitochondrial membrane permeability pore transition; NHEK, normal human epidermal keratinocyte; NMSC, nonmelanoma skin cancer; SCC, squamous cell carcinoma; TTBS, Tween-Tris base-saline.

Conflict of interest: The authors have declared that no conflict of interest exists. Citation for this article: J. Clin. Invest. 117:3753-3764 (2007). doi:10.1172/JCI32481. dimers in mammalian cells. If not repaired, these DNA lesions can lead to structurally altered DNA sequences such as $\mathrm{C}$ to $\mathrm{T}$ and CC to TT transitions, known as UVB "signature" mutations (6). Mutations in genomic DNA can lead to carcinogenesis, usually acting as an initiating event. Other genes can cooperate to influence the development of carcinogenesis, which may require multiple mutations at different loci. It is believed that 3 to 7 mutational events are needed for the transformation of normal cells into cancer cells. These mutations usually occur in tumor suppressor genes, oncogenes, and/or other genes that regulate cell proliferation (1). p53 mutations occur in the majority of SCCs, basal cell carcinomas, actinic keratoses, and perilesional nontumor skin adjacent to these lesions. These mutations are detectable early in the development of UVB-induced NMSCs $(7,8)$. In murine models, UVB-associated p53 gene mutations also contribute to tumor development and are $\mathrm{C}$ to $\mathrm{T}$ and $\mathrm{CC}$ to TT transitions at dipyrimidine sites. The dose-dependent protective role of p53 against UVB carcinogenesis can be shown using p53-/-, p53+-, and p53 wild-type mice. p53-/- mice are highly susceptible to tumor induction by UVB compared with wild-type mice, whereas $\mathrm{p} 53^{+/-}$mice show an intermediate response (9). p53 is crucial for modulating cellular and tissue responses to DNA damage resulting from various genotoxic insults such as UVB or ionizing radiation and DNA-damaging chemical compounds (5). Upregulation of wildtype p53 inhibits the cell cycle, thereby permitting DNA repair, and also can drive apoptosis by transactivating downstream target genes such as Bax. In contrast, mutant p53 cannot perform these functions, thereby allowing uncontrolled proliferation that leads to tumorigenesis $(10,11)$. 


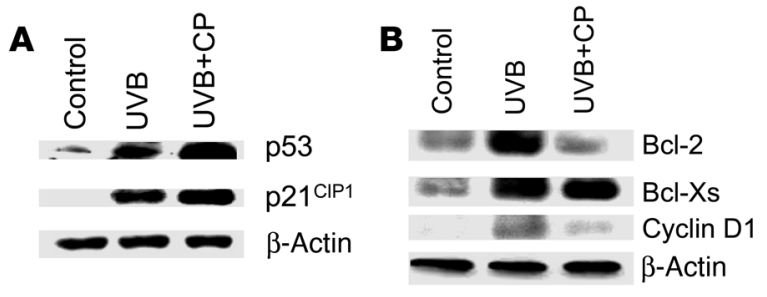

Figure 1

Effects of CP-31398 treatment on the expression of p53 target, cellcycle regulatory, and apoptosis-related proteins in the skin of mice chronically irradiated with UVB. (A) Western blot showing expression of p53 and its downstream target gene p21 ${ }^{\mathrm{CIP} 1}$ in UVB-irradiated skin of SKH-1 mice treated with CP-31398. (B) The expression of proapoptotic BcIXs, antiapoptotic Bcl2, and cell-cycle regulatory cyclin D1 in UVBirradiated skin of SKH-1 mice following CP-31398 treatment. The treatment protocol and other experimental details are provided in Methods.

Since p53 mutations are a ubiquitous marker of NMSCs and sun-exposed skin, an attractive strategy to reduce the risk of these tumors is to identify approaches to restore the tumor suppressor functions of mutant p53. Evidence in support of this concept has come from studies in transformed cells showing that delivery of wild-type $\mathrm{p} 53$ protein or conversion of mutant p53 to wild-type using sequence-specific peptides results in growth arrest followed by apoptosis $(12-15)$. These in vitro approaches have not been duplicated in vivo as a result of problems associated with predictable delivery of these protein- and peptide-based agents and/or other as-yet-undefined factors (16). This has led to a search for small molecular weight compounds capable of inducing wild-type p53 $(17,18)$, enhancing the half-life of this short-lived protein, or restoring its wild-type conformation and functionality as an entirely novel approach to inhibiting tumorigenesis in tissues harboring p53 mutations. In this regard, Foster et al. (19) screened more than 100,000 synthetic compounds and identified the styrylquinazoline compound, CP-31398. By employing a battery of tumor cells carrying wild-type as well as mutant p53, it has been shown that CP-31398 stabilizes the conformation of wild-type p53 and restores its tumor suppressor function. In additional studies, this agent was found to induce wild-type p53 (20) and to reduce the growth of implanted tumors carrying mutant p53 in athymic nude mice $(21,22)$.

Here, we investigated the chemopreventive and chemotherapeutic effects of CP-31398 in a SKH-1 murine model of UVB photocarcinogenesis. Similarly to humans who develop epidermal hyperplasia, actinic keratoses, and SCCs, these mice develop sequentially skin hyperplasia, benign squamous papillomas, and SCCs following chronic UVB. The molecular pathogenesis of the pathologic changes in these mice closely resembles that of sunexposed human skin $(23,24)$. Our results show that CP-31398 restores p53-dependent cell-cycle arrest and apoptosis in UVB-irradiated $\mathrm{p} 53^{+/+}$skin but not in UVB-irradiated $\mathrm{p} 53^{-/-}$skin. CP-31398 reduced the growth of UVB-induced tumors and afforded protection against UVB photocarcinogenesis in a standard cancer chemoprevention protocol. To further confirm that the mechanism of action of this compound in murine skin is relevant to human skin, we performed studies in A431 cells, human skin carcinoma cells that carry mutant p53. CP-31398 induced transcriptional activation of p53 followed by induction of cell-cycle arrest and apoptosis in these cells. The induction of apoptosis involved the mitochondrial translocation of $\mathrm{p} 53$, thereby signaling the release of cytochrome $c$ and activation of caspase-3. These results indicate that small molecular weight compounds such as CP-31398 can restore wild-type functionality to mutant $\mathrm{p} 53$, thereby reducing the risk of developing sunlight-induced human skin cancers carrying mutant $\mathrm{p} 53$.

\section{Results}

CP-31398 induces expression of $p 53$ and its downstream target proteins. CP-31398 is known to stabilize wild-type p53 and to restore the tumor suppressor functions of the mutant protein $(22,25,26)$. To verify whether CP-31398 administered i.p. enhances wild-type p53 function in the skin of chronically UVB-irradiated (180 millijoules $[\mathrm{mJ}] / \mathrm{cm}^{2}$ UVB twice weekly for 16 weeks) SKH-1 mice, we first tested its effects on the expression of p53-dependent downstream target genes in skin. It is known that chronic UVB irradiation of these mice leads to frequent UVB signature mutations. Also, these signature mutations are detectable long before tumors are visible either grossly or microscopically $(4,5)$. As shown in Figure 1, CP-31398 enhanced p53 and its downstream target gene, p21 (Figure 1A). In these skin samples, we also analyzed selected markers of apoptosis and cell proliferation. The antiapoptotic protein $\mathrm{Bcl} 2$ was decreased as was the cell proliferation marker, cyclin D1. In contrast, the proapoptotic protein, BclXs was increased (Figure 1B).

CP-31398 reduces the growth of UVB-induced skin tumors in SKH-1 mice. To investigate whether these effects of CP-31398 on p53 coordinated with impaired growth of UVB-induced skin tumors, we treated tumor-bearing SKH-1 mice (> 6 tumors/mouse) $\left(180 \mathrm{~mJ} / \mathrm{cm}^{2}\right.$ UVB, twice a week for 40 weeks) with CP-31398 or vehicle for 4 weeks after discontinuing UVB irradiation. Tumors in vehicletreated animals continued to grow, as shown by increases in both tumor number and tumor volume (Figure 2A). At 44 weeks, the tumor number in the controls was increased to $116 \%$ and tumor volume to $197 \%$ of the initial value recorded at week 40 . In contrast, the CP-31398-treated mice showed a decrease in tumor growth $(P<0.008)$ as well as tumor volume $(P<0.04)$. To probe the tumor inhibitory mechanism of CP-31398, we analyzed the expression of cell-cycle and apoptotic regulatory proteins in the tumors and in perilesional skin adjacent to tumors. As shown in Figure 2B, CP-31398 increased p53 expression and its downstream target genes PUMA- $\alpha$ and $\mathrm{mdm}-2$ in perilesional tumor-adjacent skin as well as in the tumors themselves. CP-31398 also diminished UVBinduced expression of cyclins A, B1, D1, and E (Figure 2C). Consistent with the observed reduction in tumor growth, proapoptotic regulatory proteins such as caspase-3 (data not shown) and PARP cleavage (Figure 2D), which were barely detectable in perilesional skin and tumors of vehicle-treated mice, were augmented by CP-31398. In addition, the antiapoptotic protein Bcl2, which is overexpressed in perilesional skin and tumors of UVB-irradiated animals, virtually disappeared following CP-31398 treatment, as shown on the Western blot (Figure 2D). Immunohistochemical analysis of these lesions showed that CP-31398 reduced staining for $\mathrm{Bcl} 2$ and enhanced Bax expression (Figure 2E).

CP-31398 treatment blocks UVB-induced photocarcinogenesis in SKH-1 mice. Next, we assessed the chemopreventive effects of CP-31398 against UVB-induced photocarcinogenesis. In this study, CP-31398 $(1.25 \mathrm{mg} / \mathrm{mouse}$, twice weekly, applied 30 minutes prior to each UVB exposure) substantially diminished UVB-induced tumors as measured by tumor number and tumor size (Figure 3, A and B) 
A
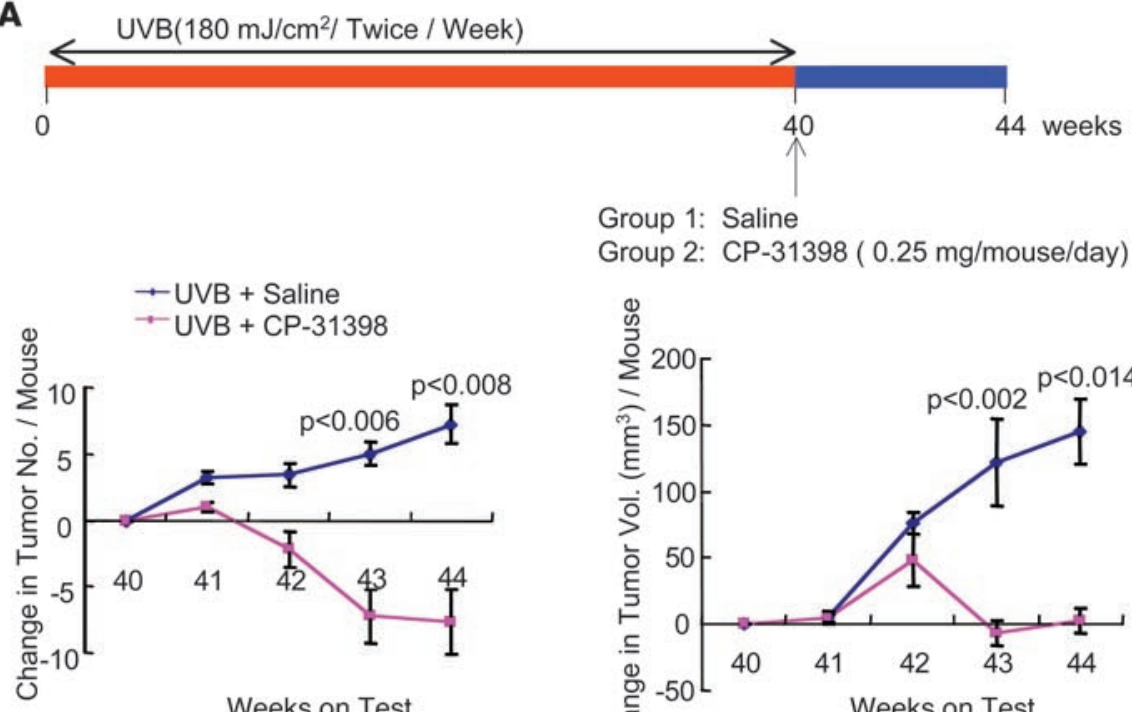

Weeks on Test

Group 2: CP-31398 ( 0.25 mg/mouse/day)
B
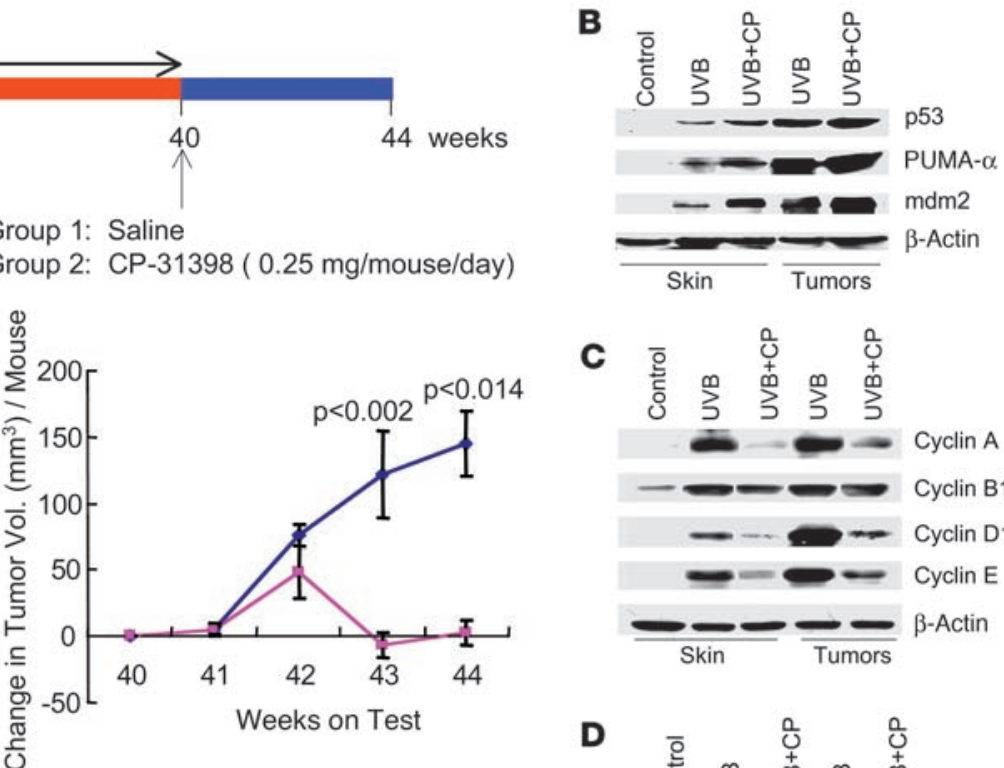

C
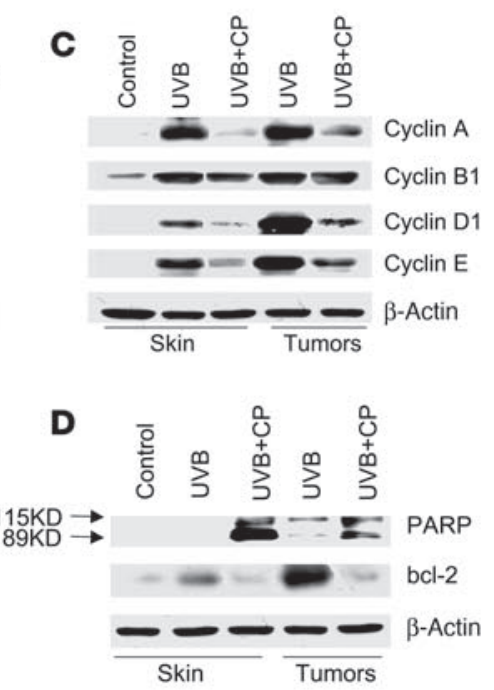

E bax

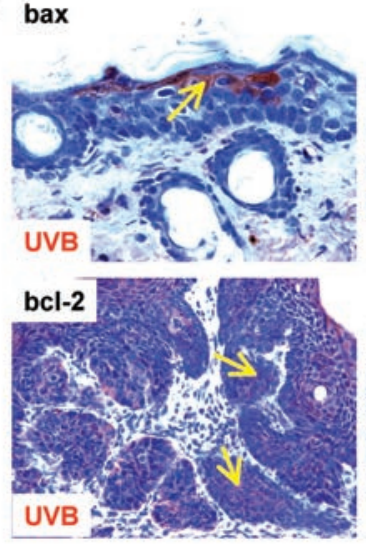

bax
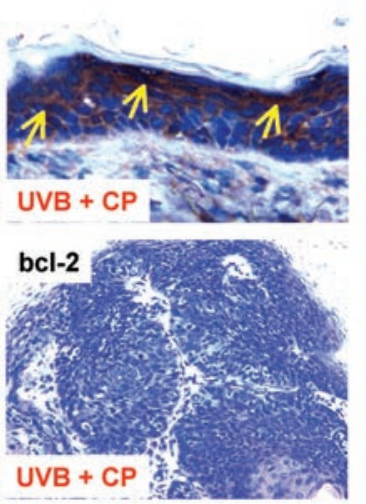

Figure 2

Effects of CP-31398 treatment on the growth of UVB-induced skin tumors in SKH-1 mice. (A) Drawing showing experimental protocol design. CP-31398 administered i.p. reduces growth of UVB-induced skin tumors in SKH-1 mice in terms of tumor number (lower left panel) and tumor volume (lower right panel). (B) Effect of CP-31398 on the expression of p53 and its downstream target genes PUMA- $\alpha$ and mdm-2 in perilesional skin and tumors. (C) Effect of CP-31398 on the expression of cyclins A, B1, D1, and E in perilesional skin and tumors. (D) PARP cleavage and expression of antiapoptotic Bcl2 in perilesional skin and tumors following CP-31398 treatment. (E) Immunohistochemical analyses showing expression of Bcl2 and Bax in UVB-irradiated skin and UVB-induced SCC following CP-31398 treatment. Arrows indicate Bax- or BCL2-expressing cells. Treatment protocol and other experimental details are provided in Methods. $P$ values represent significance when compared with vehicle-treated control at corresponding time point.

compared with vehicle-treated mice. Tumor growth suppression was consistently observed throughout the experimental protocol. TUNEL staining of paraffin sections of CP-31398 confirmed extensive apoptosis in these tissues (data not shown). As described above, CP-31398 treatment also reduced the expression of cell-cycle regulatory genes, particularly the cyclins A, B1, and D1 (Figure 3C).

CP-31398 treatment induces apoptosis in UVB-irradiated skin of $p 53^{+/+}$/ SKH-1 but not $p 53^{-/-} / S K H-1$ mice. To ascertain whether mutant p53 is required for CP-31398-mediated enhancement of apoptosis, we investigated its effects on UVB-irradiated skin of $\mathrm{p}^{5} 3^{+/+} / \mathrm{SKH}-1$ and p53-/-/SKH-1 animals. As measured by TUNEL staining (Figure 4A) and immunostaining for the mitochondrial release of Smac/Diablo (Figure 4B), CP-31398 induced apoptosis in UVB-irradiated skin of p53+/+/SKH-1 mice but not $\mathrm{p} 53^{-/-} / \mathrm{SKH}-1$ mice. These results were also confirmed by Western blot analysis of skin tissue lysates showing that CP-31398 induces expression of Bax and PARP cleavage and reduces $\mathrm{Bcl} 2$ expression in UVB-irradiated $\mathrm{p} 53^{+/+} / \mathrm{SKH}-1$ mice but not in $\mathrm{p} 53^{-/-} / \mathrm{SKH}-1$ littermates (Figure $4 \mathrm{C}$ ).

CP-31398 treatment of human epidermoid carcinoma A431 cells induces cell-cycle arrest and apoptosis. To determine whether the effects of CP-31398 that we demonstrated in murine skin tumor cells can also occur in human epidermal SCCs, we employed A431 cells, which carry mutant p53 protein incapable of binding to DNA and transactivating its target genes $(27,28)$. CP-31398 resulted in G0/G1 cell-cycle arrest at lower concentrations. However, at higher concentrations, the sub-G1 population representing apoptotic cells was increased, as shown in Figure 5A. The effect of CP-31398 at early time points was also assessed on the p53 target proteins 


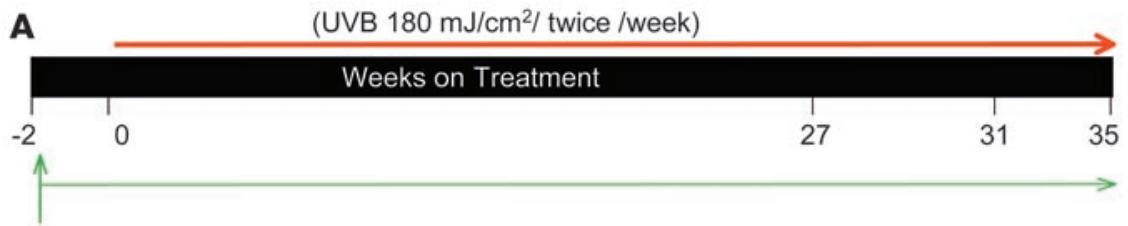

Topical Application (25 SKH-1 hairless mice/group)

Group 1: UVB + Vehicle

Group 2: UVB + CP-31398 (1.25 mg/application) twice/week

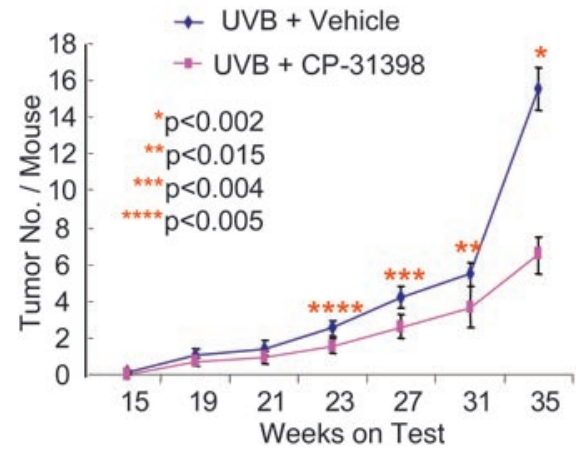

B

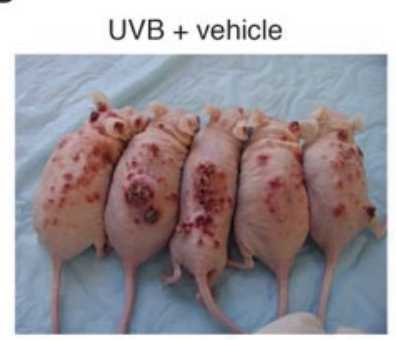

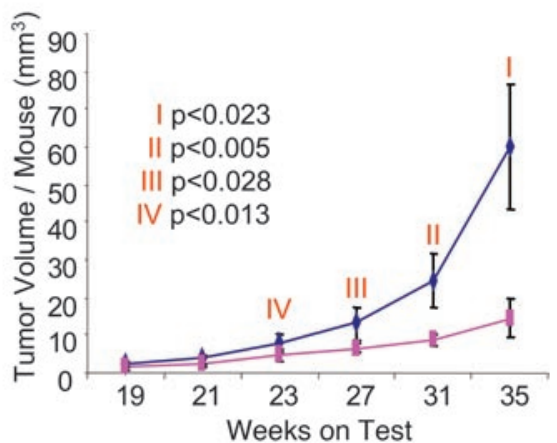

C

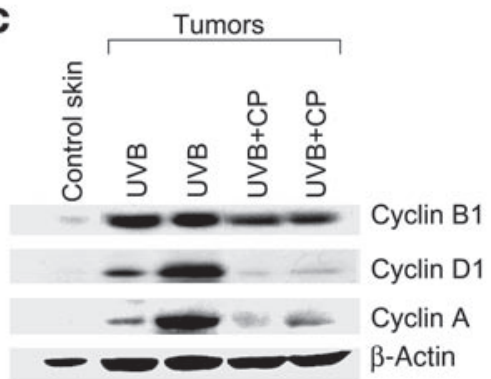

Figure 3

Chemopreventive effects of CP-31398 on UVB-induced skin photocarcinogenesis. (A) Drawing showing experimental protocol design. Topical CP-31398 reduces UVB-induced cutaneous tumor growth in terms of tumor number (lower left panel) and tumor size (lower right panel). (B) Picture of representative mice showing effects of CP-31398 on UVB-induced skin tumor development. (C) Expression of cyclins B1, D1, and A in UVB-induced skin tumors of SKH-1 mice following CP-31398 treatment. Treatment protocol and other experimental details are provided in Methods. $P$ values represent significance when compared with vehicle-treated control at corresponding time points.

p21 and mdm2. As shown in Figure 5B, the expression of these proteins was upregulated at 3 and 6 hours following treatment with CP-31398. Similar results were observed on the transcript levels of p21 (Figure 5C). It is known that p21 is required for G1 cell-cycle arrest. Next we assessed the effect of CP-31398 on the expression of proapoptotic and cell-cycle regulatory proteins in these cells. We observed a time- and dose-dependent increase in the expression of proapoptotic proteins such as Apaf-1, Bax, BclXs, $\mathrm{Bad}$, and caspase-3. PARP cleavage was also induced (Figure 6A), whereas cyclins D1, E, and B1 were decreased (Figure 6B).

To further assess apoptosis induction by CP-31398, we employed MitoCapture, a dye that accumulates and aggregates in the mitochondria of normal cells and, when examined fluorometrically, emits a characteristic bright red signal (29). In apoptotic cells, it cannot accumulate in mitochondria due to altered mitochondrial membrane potential and remains in the cytoplasm in its monomeric form, which emits bright green fluorescence. For these studies, we first used normal human epidermal kerati- nocytes (NHEKs) with wild-type p53. Using the MitoCapture dye, no change in mitochondrial fluorescence was seen after CP-31398 treatment of these cells. In contrast, CP-31398-treated A431 cells showed green fluorescence, indicating that CP-31398 only induces apoptosis in cells with mutant p53. We also stained these cells for mitochondrial proteins, cytochrome $c$, Smac, and mtHSP70. In NHEKs treated with CP-31398 or vehicle-treated A431 cells, these proteins were limited to mitochondria, whereas in A431 cells treated with CP-31398, both cytochrome $c$ and Smac were released into the cytoplasm (Figure 6C).

To confirm that CP-31398 alters mitochondrial membrane potential, we employed JC-1 dye, which accumulates in mitochondria and forms aggregates that emit red-orange fluorescence when exposed to light at $590 \mathrm{~nm}$. Formation of these aggregates requires normal mitochondrial membrane potential. With altered mitochondrial membrane potential following depolarization, the dye remains as a monomer in the cytoplasm and shows green fluorescence (30-33). The ratio of red/green fluorescence 


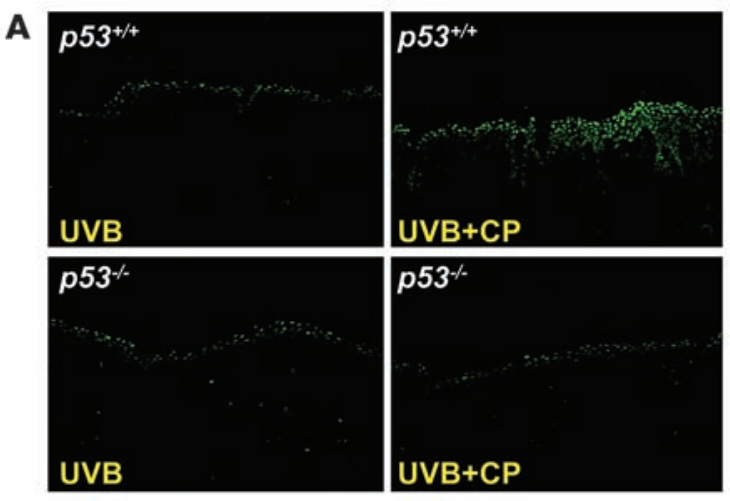

B
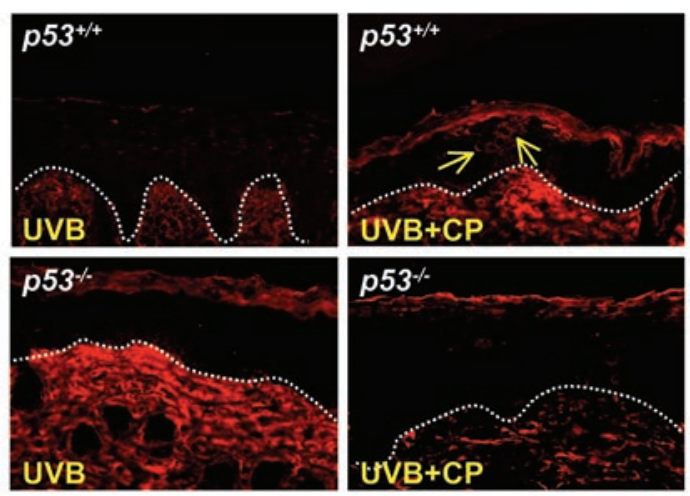

C

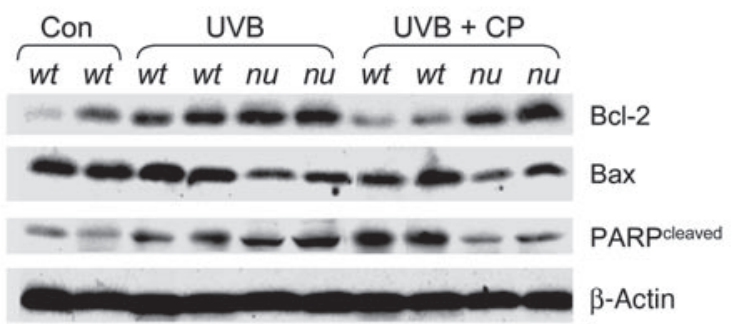

is a function of mitochondrial membrane potential. CP-31398 decreased dose dependently the mitochondrial membrane potential in A431 cells (Figure 6D).

CP-31398 induces mitochondrial translocation of mutant $p 53$, resulting in cytochrome c release and apoptosis. Next, we investigated whether CP-31398 can enhance translocation of mutant p53 to mitochondria. It is known that wild-type but not mutant p53 migrates to mitochondria in response to genotoxic insult (34) and that wildtype p53 alters mitochondrial membrane potential $(35,36)$, leading to release of cytochrome $c$ followed by apoptosis. In this experiment, we employed MitoTracker red dye to stain mitochondria of vehicle- or CP-31398-treated A431 cells. The localization of p53 in mitochondria (stained in green) was confirmed by the yellow color in the overlay. Thus CP-31398 enhanced p53 mitochondrial localization (Figure 7A), whereas no such effect was discernible in control cells. To further document that translocated mutant p53 after CP-31398 treatment colocalizes with mitochondrial proteins as does wild-type p53 (37), we immunoprecipitated mutant p53 from mitochondrial protein extracts of A431 cells and blotted it with manganese superoxide dismutase (MnSOD), a mitochondrial protein. We also performed a reverse experiment in which we immunoprecipitated MnSOD and blotted it with p53. In both

\section{Figure 4}

Effects of CP-31398 treatment on the induction of apoptosis in the skin of UVB-irradiated $\mathrm{p} 53^{+/+} / \mathrm{SKH}-1$ and $\mathrm{p} 53^{-/-/ S K H-1}$ mice. (A) TUNEL staining showing CP-31398-induced apoptosis in UVB-irra-

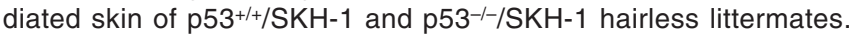
(B) Immunostaining for Smac/Diablo in epidermis of UVB-irradiated skin of $\mathrm{p} 53^{+/+} / \mathrm{SKH}-1$ and $\mathrm{p} 53^{-/-} / \mathrm{SKH}-1$ hairless littermates following CP-31398 treatment. Arrows show release of Smac from mitochondria to cytoplasm. (C) Western blot showing the expression of Bcl2, Bax, and PARP cleavage in UVB-irradiated skin of p53 $3^{+/ /} / \mathrm{SKH}-1$ and $\mathrm{p} 53^{-/-/}$ $\mathrm{SKH}-1$ hairless littermates. Treatment protocol and other experimental details are provided in Methods.

instances, a positive p53 signal was seen in CP-31398-treated cells but not in untreated or vehicle-treated control cells (Figure 7B).

Cyclosporine A blocks CP-31398-mediated mitochondrial localization of p53 and consequent induction of apoptosis in A431 cells. Cyclosporine A is known to be a potent and specific inhibitor $(38,39)$ of mitochondrial membrane permeability pore transition (MPT). We employed this agent to determine whether MPT blockade in A431 cells inhibits CP-31398-mediated p53 mitochondrial translocation and the associated alterations in mitochondrial membrane potential, cytochrome $c$ release, and induction of apoptosis. As shown in Figure 7C, cyclosporine A pretreatment blocked mitochondrial p53 translocation, which was accompanied by restoration of mitochondrial membrane potential (Figure 7D). Concomitantly, mitochondrial cytochrome $c$ release into the cytoplasm was diminished (Figure 7E), and CP-31398-mediated apoptosis was abrogated (Figure 7D).

\section{Discussion}

p53 is known to be a potent tumor suppressor and functions as a tetrameric transcription factor by binding to specific DNA sequences and transactivating or repressing a large number of target genes involved in cell-cycle regulation and apoptosis (40). It is also known that most p53 mutations in human cancers, including those induced by UVB in skin, occur in its DNA-binding domain. Accordingly, structurally altered mutant $\mathrm{p} 53$ proteins cannot bind to DNA and lose their ability to transactivate target genes $(3,9)$. Wild-type p53 has a very short half-life ( $<30 \mathrm{~min})$ and is degraded rapidly due to its ability to induce components that regulate its own negative feedback, such as MDM2 or Pirh2 (41). In contrast, mutant p53 is more stable and can be detected at high levels in tumor cells (42). We have previously shown that p53 accumulates in UVB-induced skin tumors and in adjacent perilesional non-tumor-bearing skin (43). Therefore, it seems plausible that restoration of wild-type function in tumor cells with mutant p53 may have preventive/therapeutic effects in tumors. Indeed, there have been several recent publications documenting the remarkable antitumor effects of restoring wild-type p53 in various types of tumors employing various molecular genetic approaches (refs. 44-46 and references cited therein). To this end, the identification of CP-31398 as well as other chemical agents such as PRIMA-1 that enhance levels of wild-type p53 could be a useful pharmacological approach to cancer treatment/prevention (21, 47-50). To date, this promise has not been realized, perhaps because many of the studies with these agents have been conducted in cultured cells or in xenograft murine models, which are immunosuppressed and therefore may have limited relevance to human carcinogenesis (51). In this study, we used specially designed murine models to demonstrate that CP-31398 reverts mutant p53 to wild-type func- 


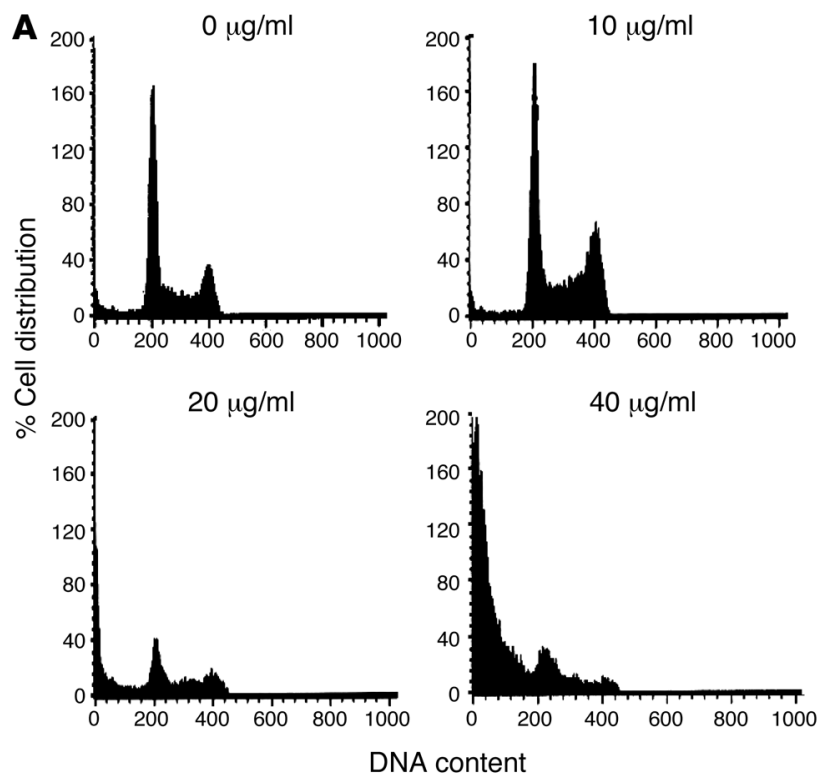

B

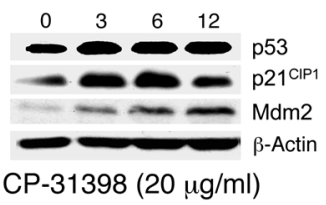

C

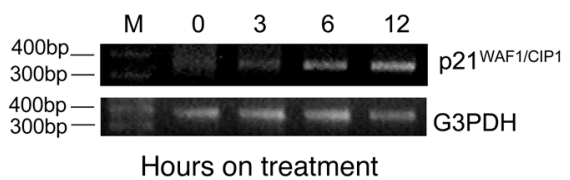

tion. The observation that topical as well as i.p. administration of CP-31398 results in the activation of p53 target genes, such as $\mathrm{p} 21, \mathrm{mdm} 2$, and PUMA- $\alpha$, in skin tumors and in adjacent perilesional skin of chronically UVB-irradiated mice suggests that this compound can restore the DNA-binding and transcription-activating function of mutant $\mathrm{p} 53$. In our previous studies, we showed that UVB-induced SCCs carry p53 mutations in the DNA-binding domain (43). These observations are consistent with other reports showing that CP-31398 induces p53 target genes in a variety of epithelial cancer cells carrying mutant p53. For example, in colon and prostate carcinoma cells treated with CP-31398, there is enhanced expression of $\mathrm{p} 53$-responsive genes and apoptosis accompanied by altered levels of Bcl2 and Bax (the Bcl2/Bax ratio is a critical determinant of apoptosis) $(36,19)$. In addition, our observations that CP-31398 can block the growth of UVB-induced SCCs further support the notion that chemical agents capable of refolding mutant p53 to wild-type conformation can be of great therapeutic application. This may also be true for a variety of other extracutaneous cancers carrying mutant $\mathrm{p} 53$. Restoration of p53 tumor suppressor function in the skin of UVB-irradiated animals by CP-31398 in our studies is also supported by the diminished expression of regulatory proteins involved in cell-cycle progression and proliferation (52). Furthermore, this compound enhanced apoptosis in UVB-induced tumors, as shown by reduced $\mathrm{Bcl} 2$ and enhanced Bax expression and augmented PARP cleavage. Our results confirm earlier observations in colon, lung, and many other cancer cells where CP-31398 induced apoptosis by activat-

\section{Figure 5}

Effects of CP-31398 treatment on cell-cycle progression in human epidermoid carcinoma A431 cells. (A) CP-31398 induces cell-cycle arrest in A431 cells. (B) Western blot showing the expression of p53 and its downstream target genes $\mathrm{p} 21^{\mathrm{CIP} 1}$ and $\mathrm{mdm} 2$ in A431 cells treated with CP-31398. (C) RT-PCR showing mRNA levels of p21 CIP1 in CP31398-treated A431 cells. A431 cells were treated with PBS (control) or various concentrations of CP-31398 for different time intervals as indicated in the figure. For Western blot analysis, $100 \mu \mathrm{g}$ protein was loaded in each well. Each experiment was repeated at least 3 times.

ing the intrinsic Bax/mitochondrial apoptosis pathway (53-57). It is known that $\mathrm{p} 53$ upregulates Bax, a proapoptotic member of the Bcl2 family that is localized on the outer mitochondrial membrane (36). It is also possible that CP-31398 enhances wild-type p53 activity by diminishing the degradation of the protein (20). Thus, the abrogation of tumor growth as well as cell-cycle inhibitory and apoptosis-promoting effects of CP-31398 observed here may also be a result of newly synthesized p $53(56,58,59)$. Our results showing that apoptosis is enhanced only in UVB-irradiated SKH-1 mice carrying wild-type p53 suggest that CP-31398 exerts its effects in the presence of mutant p 53. However, we were unable to carry out UVB-induced tumorigenesis studies in $\mathrm{p} 53^{-/-} / \mathrm{SKH}-1$ mice employing CP-31398, as these animals die prematurely of malignant lymphomas well before the appearance of UVB-induced skin tumors. This is also substantiated by prior published studies (9). Similar to our own experience, these authors also noted that $\mathrm{p} 53^{-/-}$hairless mice die prior to manifesting skin photocarcinogenesis. Moreover, we observed that ptc1 $1^{+/} / \mathrm{SKH}-1$ hairless mice spontaneously developed rhabdomyosarcomas, which are unaffected by CP-31398 treatment. To determine whether the ineffectiveness of CP-31398 in blocking the spontaneous growth of rhabdomyosarcomas in these animals is related to p 53 mutations, we analyzed these spontaneously induced rhabdomyosarcomas and found that these tumors carry no p53 mutations in the DNAbinding domain. From these results, we conclude that the ineffectiveness of CP-31398 in blocking the growth of rhabdomyosarcomas is likely due to absence of mutant p53 in these tumors (our unpublished results). Therefore, the observed efficacy of CP-31398 in reducing UVB-induced SCCs in this study indicates that p53 is a major target for the chemoprevention and treatment of this type of NMSC. Taken together, our data indicate that CP-31398 and perhaps other similar small molecular weight compounds are capable of restoring wild-type functionality of mutant p53.

To further validate the possible efficacy of CP-31398 in human SCCs, we investigated its effects in human epidermoid carcinoma A431 cells. A431 cells carry a mutation in codon 273, R273H (Arg to His) of the p53 gene that abolishes its ability to transactivate its downstream target genes $(27,28)$. Interestingly, we observed that CP-31398 induces p 53 downstream target genes p21, mdm2, and Bax in these cells. This is consistent with the results of Foster et al., who demonstrated a similar increase in p53 target genes as well as in p53 reporter gene expression in colon carcinoma cells by CP-31398 (19). Although there are differences in the occurrence of UVBinduced hot spot mutations in human and murine skin tumors (for example, mutations at 247-248 and 278-279 are known to occur in humans but are absent in murine skin tumors) (60), the relative importance of clones harboring these mutations in terms of their aggressiveness and metastatic potential has not been defined. The ability of CP-31398 to interact with these clones is also unpredict- 
A

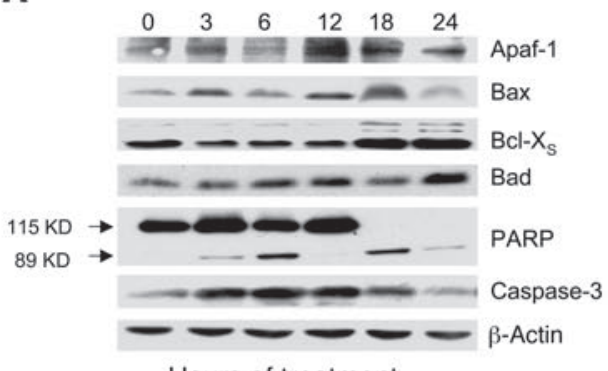

Hours of treatment
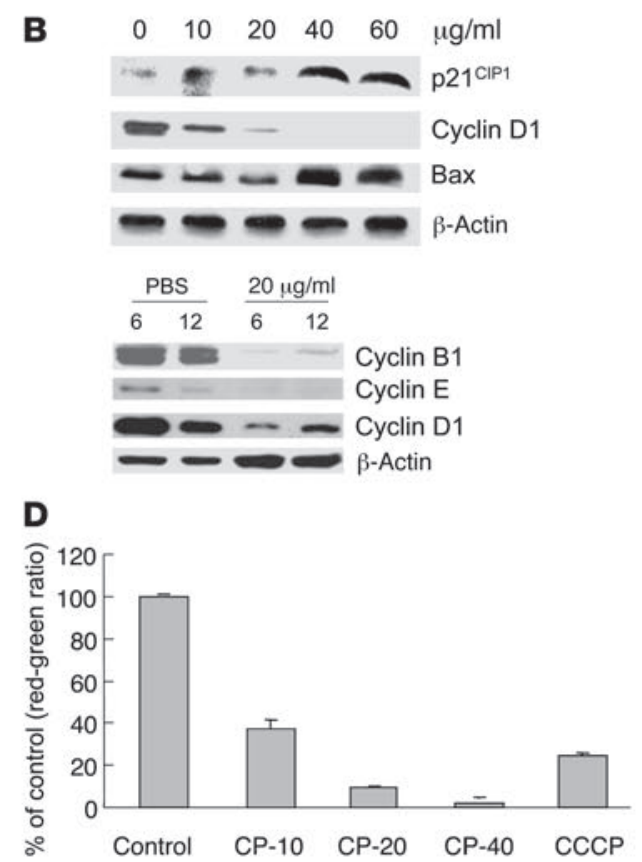

able at this stage, though it is known that CP-31398 kills cancer cells harboring distinct mutations with different sensitivities $(56,58,59)$. Nonetheless, both murine and human SCCs that we tested in this study were found sensitive to CP-31398, and both were killed by activating mitochondrial-dependent apoptosis induction.

To probe the mechanism of action of CP-31398, we investigated its effects on the migration of p53 to the mitochondria. It is known
C
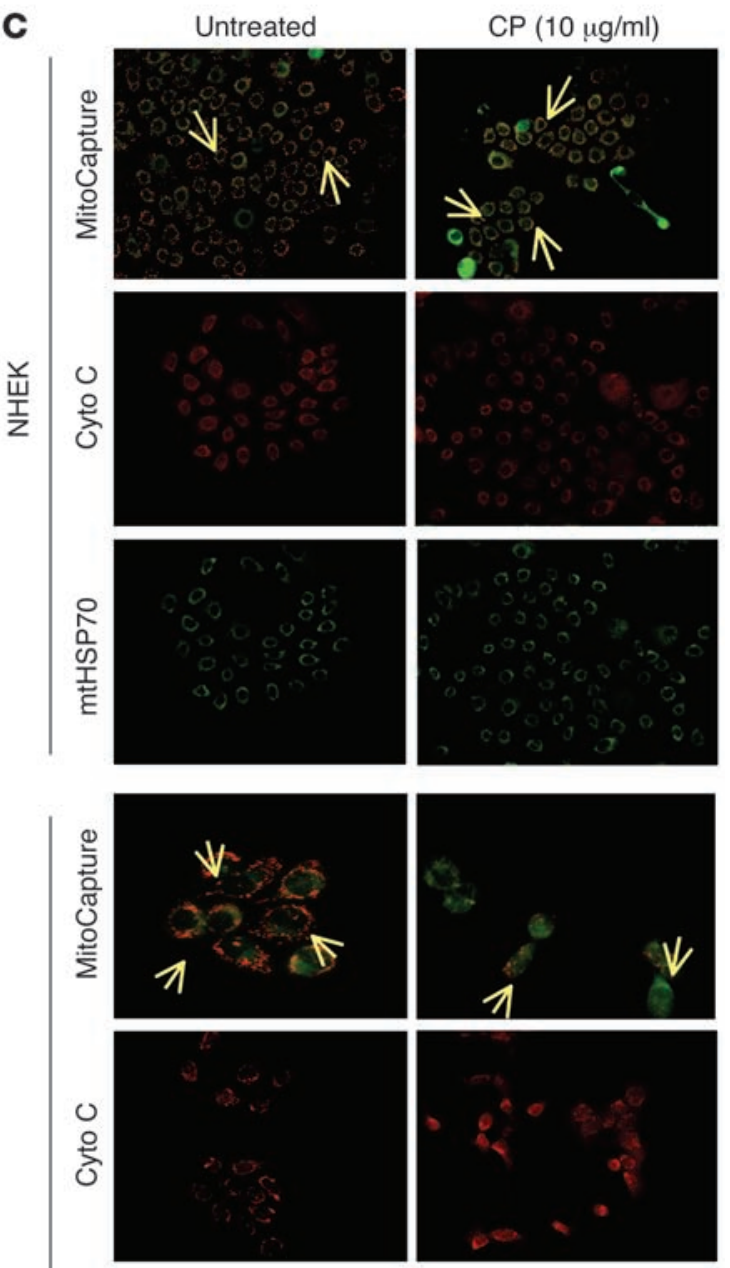

产
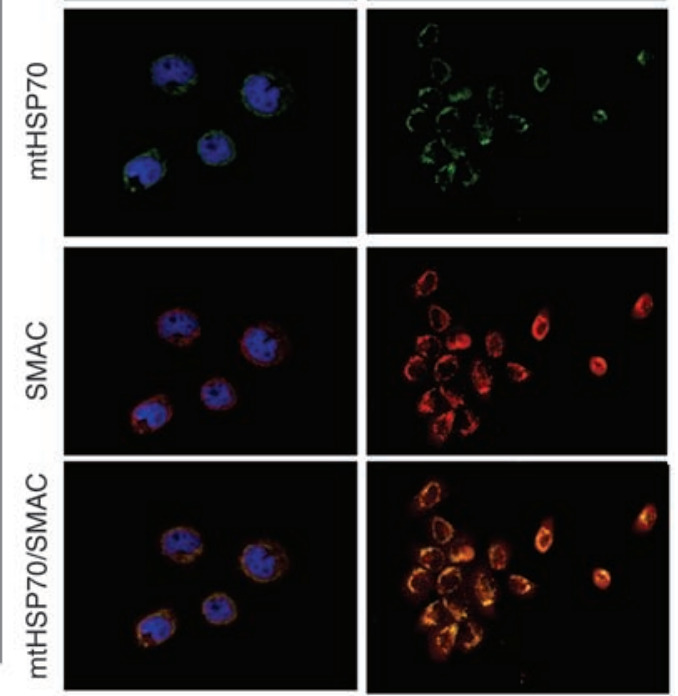

\section{Figure 6}

Effects of CP-31398 treatment on the induction of apoptosis in neonatal human epidermal keratinocytes and human epidermoid carcinoma A431 cells. (A) Western blot showing the expression of apoptosis proteins. (B) Western blot showing the expression of cell-cycle regulatory proteins in A431 cells following CP-31398 treatment. (C) Effect of CP-31398 on the induction of apoptosis and release of mitochondrial proteins in NHEKs carrying wildtype p53 and A431 cells carrying mutant $p 53$. (D) Effect of CP-31398 on the changes in mitochondrial membrane potential in A431 cells. A431 cells were treated with PBS (control) or various concentrations of CP-31398 as indicated in the figure for different time intervals. For Western blot analysis, $100 \mu \mathrm{g}$ protein was loaded in each well. Each experiment was repeated at least 3 times. For assaying mitochondrial membrane potential, A431 cells were treated with PBS (control) or 10,20 , and $40 \mu \mathrm{g} / \mathrm{ml}$ of CP-31398 for 10 minutes and stained with $\mathrm{JC}-1$ dye. Carbonyl cyanide 3-chlorophenylhydrazone (CCCP) was used as positive control. Error bars represent mean $\pm S D$ of triplicate samples. 

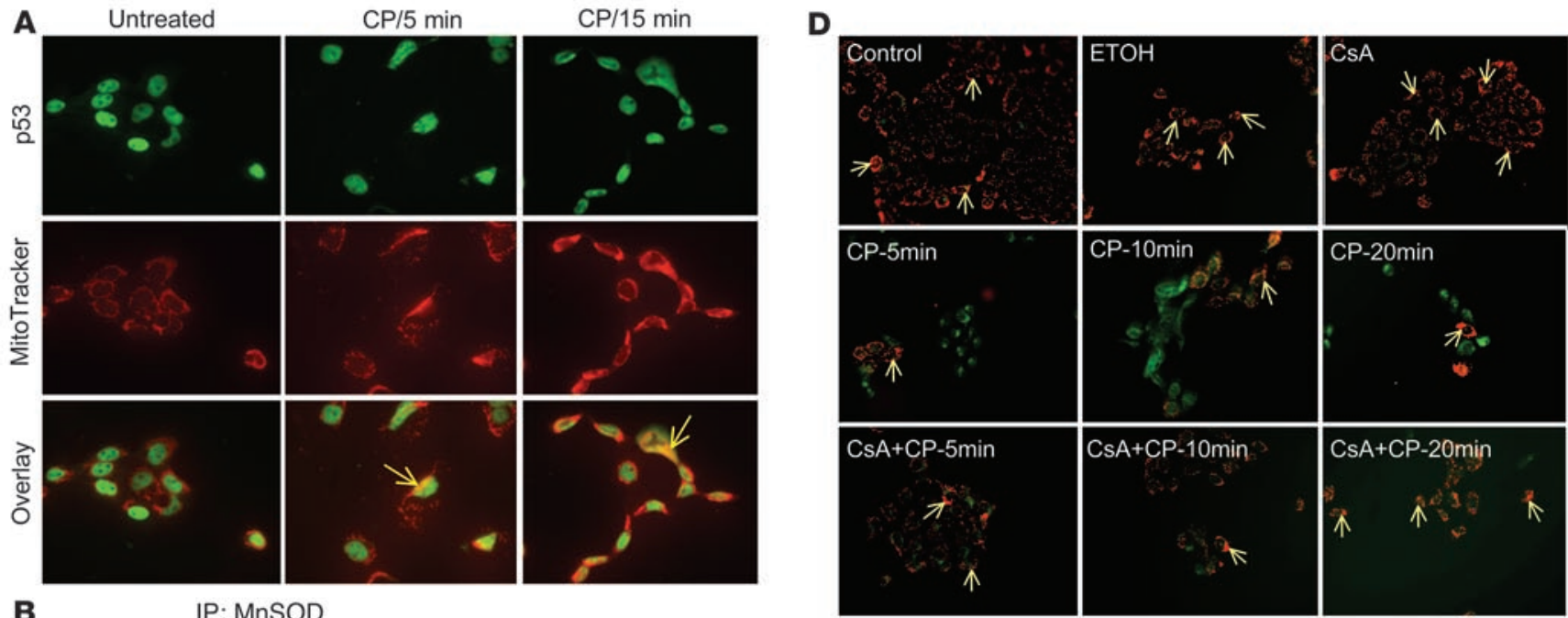

B IP: MnSOD
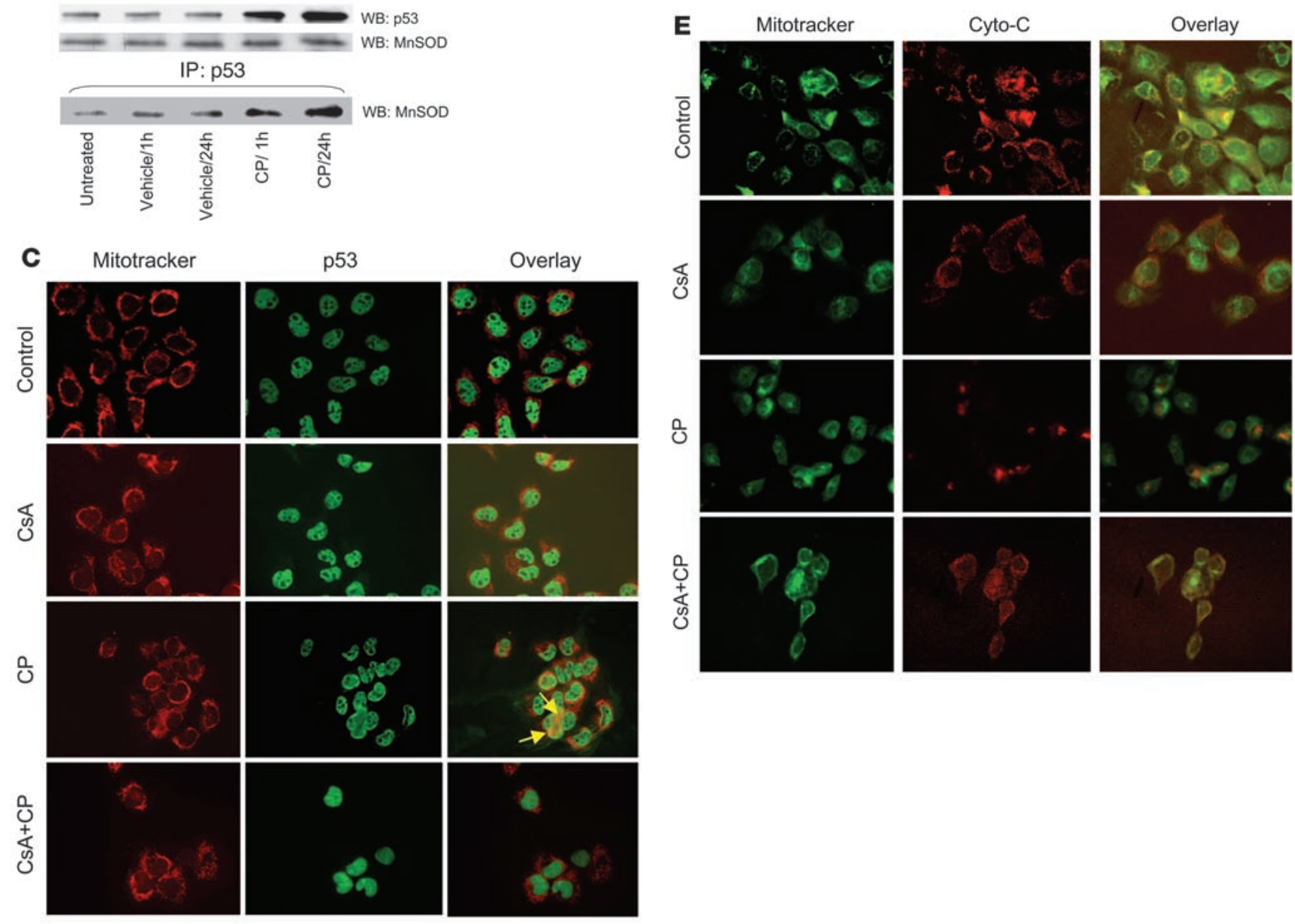

Figure 7

Effects of CP-31398 on the translocation of p53 to mitochondria, alternations in MPT potential, and release of cytochrome $c$. (A) Immunofluorescence staining showing colocalization of p53 with MitoTracker, which stains for mitochondria. (B) Western blots of immunocoprecipitates of p53 and mitochondrial MnSOD from mitochondrial protein extracts prepared from CP-31398-treated, vehicle-treated, and untreated A431 cells. (C) Immunofluorescence staining showing cyclosporin A blocks CP-31398-induced migration of p53 to mitochondria of A431 cells. (D) Immunofluorescence staining (using MitoCapture) showing cyclosporin A blocks CP-31398-induced apoptosis in A431 cells. Arrows indicate localization of p53 in mitochondria in $\mathbf{A}$ and $\mathbf{C}$, whereas in $\mathbf{D}$, arrows show live cells with red fluorescence and green fluorescence representing cells undergoing apoptosis. (E) Immunofluorescence staining showing cyclosporin A blocks CP-31398-induced release of cytochrome $c$ in A431 cells. A431 cells were treated with PBS (control) or various concentrations of CP-31398 for different time intervals as described in Methods or indicated in the figure. Each experiment was repeated at least 3 times. For immunoprecipitation followed by Western blot analysis, $300 \mu \mathrm{g}$ protein was used. 


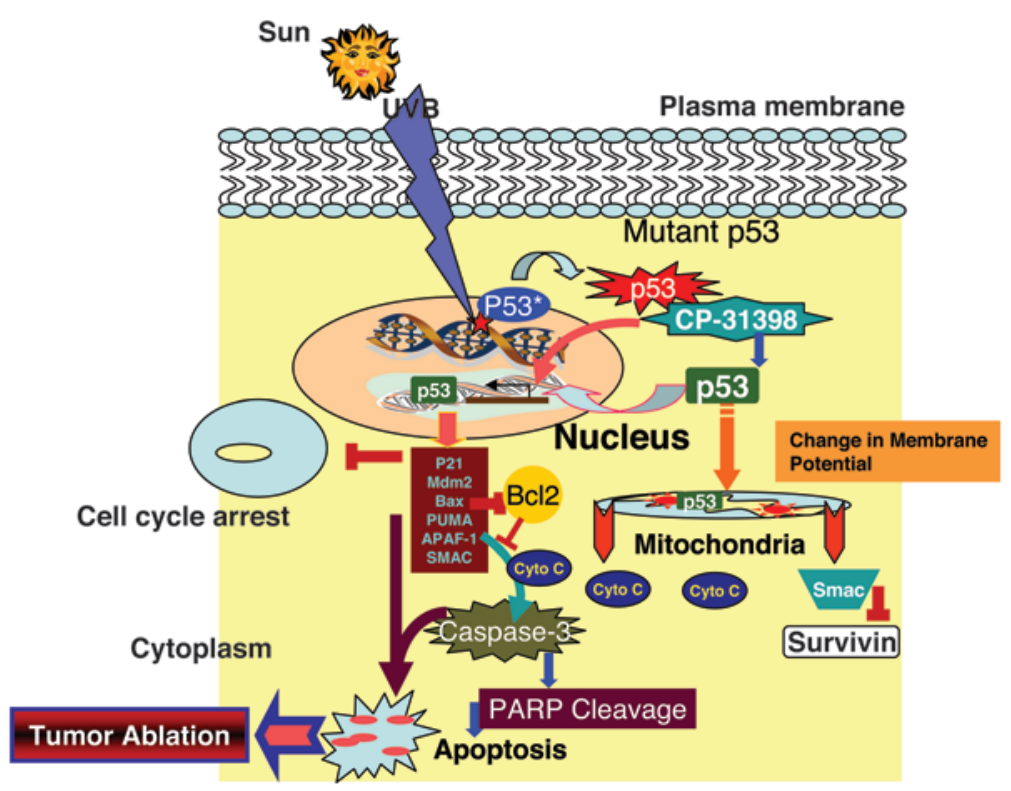

\section{Figure 8}

Cascade of events occurring during CP-31398-mediated activation of mutant p53 to wild-type function. CP-31398 interacts with mutant p53 and restores its wild-type function, including transcriptional activation of its target genes, such as p21, mdm2, puma, bax, and apaf-1. The enhanced transcription and translation of these genes led to cell-cycle arrest followed by apoptosis. The mechanism of apoptosis induction involves translocation of p53 to mitochondria, and that alters MPT, which is followed by the release of mitochondria-localized cytochrome $c$ and Smac/Diablo. Smac/ Diablo release leads to blockade of the survivin function and results in the activation of caspase-3. Activation of this pathway triggers apoptosis in tumor cells carrying mutant p53, ultimately leading to tumor ablation.

mitochondria where it disrupts permeability pores $(34,61)$, which precedes the release of mitochondrial proteins to the cytosol. This was verified using cyclosporine A, a potent blocker of MPT (38). This compound blocked p53 mitochondrial translocation and inhibited CP-31398-mediated effects on apoptosis in these cells.

Mutant p53 is essential for the effect of CP-31398 on apoptosis, as shown by our results in NHEKs carrying wild-type p53 in which no effect on apoptosis was seen; however, in A431 cells, alterations in mitochondrial membrane potential occurred with the simultaneous release of mitochondrial proteins that are markers of apoptosis including cytochrome $c$, Smac, etc. Furthermore, the treated A431 cells underwent cell-cycle arrest just as we showed in the murine skin tumor cells, which show induction of cell-cycle inhibitory protein p21. As shown in Figure 8, CP-31398 triggered a cascade of events that blocked the pathogenesis of UVB-induced skin cancer in murine models as well as in human skin cancer cells carrying mutant $\mathrm{p} 53$.

Our results indicate that CP-31398 is an effective topical chemopreventive and chemotherapeutic agent that can abrogate the growth of UVB-induced skin tumors. This compound activates p53-dependent downstream target genes that inhibit cell proliferation and cell-cycle progression, and it drives the induction of apoptosis by enhancing mitochondrial localization of the 553 protein.

\section{Methods}

\begin{abstract}
Animals
SKH-1 hairless mice. Female SKH-1 hairless mice (4-6 weeks old) were purchased from Charles River Laboratories. After adaptation to the animal facility for at least 1 week, they were housed under standard conditions (fluorescent lighting, 12 hours/day; room temperature, $23-25^{\circ} \mathrm{C}$; and relative humidity, 45\%-55\%). Mice were given water and Purina Laboratory Chow 5001 diet (Ralston-Purina Co.) ad libitum. All experiments were approved by the Columbia University Institutional Animal Care and Use Committee.

p53-//SKH-1 hairless mice. Female breeders (6-7 weeks old) of $\mathrm{p}^{53^{-/-} /}$ C57BL/6J strain were purchased from the Jackson Laboratory and were acclimatized for 1 week before being recruited to breeding. The male breed-
\end{abstract}

ers of SKH-1 hairless strain (5-6 weeks old) were purchased from Charles River Laboratories and also acclimatized for a week as described earlier. One male and 1 female mouse were kept together in individual cages for mating. Usually, it takes 5 to 10 days to get confirmed pregnancies, after which the males and females are separated. Pregnancy was confirmed by plug formation test. Twenty-one days after birth, the litters were separated from their mothers. At the age of 4 weeks, these animals were sexed and separated. Genotyping of these animals was done by tail clipping at the age of 2 weeks. A 3-mm piece of tail was taken for DNA extraction. The $\mathrm{p} 53^{+/+}$, $\mathrm{p} 53^{+/-}$, and $\mathrm{p} 53^{-/-}$mice were classified based on a simple PCR reaction using primers CCCGAGTATCTGGAAGACAG and ATAGGTCGGCGGTTCAT for wild-type and CTTGGGTGGAGAGGCTATTC and AGGTGAGATGACAGGAGATC for null animals. p53 $3^{+/-}$hairless SKH-1 mice (F2) were selected from intergeneration crosses among F1 littermates. These mice were then backcrossed for 9 generations onto SKH-1 hairless mice to minimize the $\mathrm{C} 57 \mathrm{BL} / 6 \mathrm{~J}$ genetic background, resulting in a colony of $\mathrm{p} 53^{+/-}$ $\mathrm{SKH}-1$ mice. Littermates of these mice were crossed to generate $\mathrm{p} 53^{-/-1}$ SKH-1 mice (F10), which were employed for the experiments described in this manuscript. The $\mathrm{p} 53^{+/+} / \mathrm{SKH}-1$ littermates were used as controls.

\section{Experimental protocols}

UV light source. We used a UV Irradiation Unit (Daavlin Co.) equipped with an electronic controller to regulate dosage as described earlier (43).

Cell culture. A431 cells were cultured in DMEM supplemented with heat-inactivated $10 \%$ fetal bovine serum, $100 \mathrm{U} / \mathrm{ml}$ of penicillin, and 100 $\mu \mathrm{g} / \mathrm{ml}$ of streptomycin at $37^{\circ} \mathrm{C}$ in a humidified atmosphere of $5 \% \mathrm{CO}_{2}$. However, NHEKs were cultured in a defined keratinocyte-SFM medium (Gibco; 10785-012) with growth supplement (10784-015; Gibco) at $37^{\circ} \mathrm{C}$ in a humidified atmosphere of $5 \% \mathrm{CO}_{2}$.

Treatments. Cells were grown in $100-\mathrm{mm}$ plates at $80 \%$ confluency and treated with $0,1,5,10,20$, and $40 \mu \mathrm{g} / \mathrm{ml}$ of CP-31398 for 24 hours or with $20 \mu \mathrm{g} / \mathrm{ml}$ of CP-31398 for 0, 3, 6, 12, 18, and 24 hours. Following treatment, cells were harvested and lysed in $100 \mu$ l of RIPA lysis buffer as described below.

Preparation of cell lysate. Various control and treatment cells in culture were harvested and lysed in $100 \mu \mathrm{l}$ of RIPA lysis buffer $(150 \mathrm{mM} \mathrm{NaCl}, 1 \%$ NP-40, 0.5\% sodium deoxycholate, $0.1 \%$ SDS, $50 \mathrm{mM}$ Tris, $\mathrm{pH}$ 8.0, $0.5 \mathrm{mM}$ $\mathrm{Na}_{3} \mathrm{VO}_{4}, 1 \mathrm{mM}$ DTT, $10 \mathrm{nM}$ okadaic acid, complete EDTA free proteinase 
inhibitor). These samples were then incubated on ice for 20 minutes, vortexed, and centrifuged at $12,000 \mathrm{~g}$ for 10 minutes at $4^{\circ} \mathrm{C}$. The supernatant was collected, and a Bradford assay was performed to determine the protein concentration. The samples were stored at $-80^{\circ} \mathrm{C}$ until use.

Western blotting. $100 \mu \mathrm{g}$ of total protein was separated on a $10 \%$ SDSPAGE gel and blotted onto nitrocellulose membrane. After transfer, nonspecific sites were blocked with $5 \%(\mathrm{w} / \mathrm{v})$ nonfat-dry milk in Tween-Tris base-saline (TTBS) (0.1\% Tween-20, $20 \mathrm{mM}$ Tris base, $137 \mathrm{mM} \mathrm{NaCl}$, $3.8 \mathrm{mM} \mathrm{HCl}, \mathrm{pH}$ 7.6) for 2 hours at ambient temperature followed by overnight probing with primary antibody at $4^{\circ} \mathrm{C}$. After washing the blot 3 times in TTBS for 10 minutes each, the membrane was incubated for 1 hour with horseradish peroxidase-conjugated secondary antibody (dilution-1:10,000; Jackson Laboratories). The blot was washed 3 times in TTBS for 10 minutes each time and was developed with ECL according to the manufacturer's instructions (Amersham).

FACS analysis. Cells were grown in $100-\mathrm{mm}$ plates and treated at $80 \%$ confluency with $0,1,5,10,20$, and $40 \mu \mathrm{g} / \mathrm{ml}$ of CP-31398 for 24 hours. Thereafter, these cells were collected by trypsinization and pelleted by centrifugation at $1,500 \mathrm{~g}$ for 5 minutes and fixed in ice-cold $100 \%$ alcohol for 30 minutes at $-20^{\circ} \mathrm{C}$. The other steps in this protocol included pelleting at $400 \mathrm{~g}$ for 3 minutes at $4^{\circ} \mathrm{C}$, resuspending in $0.5 \mathrm{ml}$ of $1 \times \mathrm{PBS}$ and $10 \mu \mathrm{g} / \mathrm{ml}$ of RNase $\mathrm{A}$, and then incubating for 30 minutes at $37^{\circ} \mathrm{C}$. After incubation, $50 \mu \mathrm{g} / \mathrm{ml}$ of propidium iodide was added, and the samples were then analyzed by flow cytometry.

Detection of apoptosis. A431 cells $(10,000)$ were seeded in 8-well Lab-Tek Chamber Slides with Cover (Nalge Nunc International) in $400 \mu \mathrm{l}$ medium and incubated overnight. Twenty-four hours after plating, the cells were treated with CP-31398 $(20 \mu \mathrm{l} / \mathrm{ml}$ and $40 \mu \mathrm{l} / \mathrm{ml})$ for 6 hours. After washing with cold PBS ( $\mathrm{pH} 7.4$ ), apoptosis was detected in these cells using MitoCapture Apoptosis Detection Kit (475866; Calbiochem) following the manufacturer's guidelines.

Fluorescent staining of p53. A431 cells $(15,000)$ were seeded in 4-well Lab-Tek Chamber Slides with Cover (Nalge Nunc International) in $1 \mathrm{ml}$ medium and incubated overnight. Twenty-four hours after plating, cells were incubated with $200 \mathrm{nmol} / \mathrm{l}$ of MitoTracker Red CMXRos (Molecular Probes) in culture medium for 30 minutes, after which the dye was removed and cells were treated with CP-31398 $(20 \mu \mathrm{g} / \mathrm{ml})$ for 5 or $15 \mathrm{~min}$ utes. Cells were washed and fixed with $4 \%$ paraformaldehyde for $15 \mathrm{~min}$ utes at room temperature, rinsed with cold PBS ( $\mathrm{pH} 7.4$ ), and then permeabilized with $0.5 \%$ Triton $\mathrm{X}-100$ for 10 minutes at room temperature. After blocking with goat serum (10\%) in 0.1\% BSA/PBS, p53 antibody (FL-393) was added (1:100 dilution with $4 \%$ of goat serum in $2 \% \mathrm{BSA} / \mathrm{PBS})$, and cells were incubated at $37^{\circ} \mathrm{C}$ for 1 hour followed by incubation with antimouse IgG-FITC (Sigma-Aldrich; 1:500 dilution with 2\% BSA/PBS) for 1 hour. After removal of antibodies, cells were rinsed with PBS and mounted with mounting medium containing DAPI. Fluorescence was immediately recorded on an Olympus EX51 microscope.

Mitochondrial potential alterations-based assay for apoptosis. For detecting mitochondrial potential, A431 cells $(10,000)$ were seeded in 4-well Lab-Tek Chamber Slides with Cover (Nalge Nunc International) in $1 \mathrm{ml}$ medium and were incubated overnight. Twenty-four hours after plating, cells were treated with CP-31398 $(20 \mu \mathrm{l} / \mathrm{ml}$ and $40 \mu \mathrm{l} / \mathrm{ml})$ for 6 hours and washed with cold PBS ( $\mathrm{pH}$ 7.4). We used MitoCapture Apoptosis detection kit (475866; Calbiochem) according to the manufacturer's guidelines to record the mitochondrial potential.

Mitochondrial membrane potential assay. Mitochondrial membrane potential in A431 cells treated with vehicle or CP-31398 was quantified using JC-1 dye $\left(5,5^{\prime}, 6,6^{\prime}\right.$-tetrachloro-1,1',3,3'-tetraethyl benzimidazolocarbocyanine iodide) with the staining kit obtained from Molecular Probes Inc. (no. M34152). For this, cells from various treatments were trypsinized, resuspended in $200 \mathrm{nM}$ of $\mathrm{JC}-1$ reagent solution at a concentration of $1 \times 10^{6} \mathrm{cells} / \mathrm{ml}$ in triplicate, and then incubated for 20 minutes in a $5 \%$ $\mathrm{CO}_{2}$ incubator at $37^{\circ} \mathrm{C}$. Thereafter, these cells were centrifuged, the supernatant removed, and cell pellets were resuspended in $0.5 \mathrm{ml}$ PBS buffer and then immediately analyzed on a flow cytometer. $5 \mu \mathrm{M}$ of carbonyl cyanide 3-chlorophenylhydrazone was used to completely disrupt mitochondrial potential as a positive control.

Immunofluorescence staining. To detect cytochrome $c$, mthsp70, and Smac, cells were fixed with $4 \%$ paraformaldehyde for 10 minutes, washed with PBS, and then permeabilized with $0.2 \%$ Triton $\mathrm{X}-100$ for 5 minutes at room temperature and blocked with $10 \%$ goat serum for 30 minutes at room temperature. These cells were then stained with a specific antibody against cytochrome $c$ (556433; BD Biosciences - Pharmingen) or mthsp70 (MA3-028; Affinity BioReagents) followed by Alexa Fluor IgG-conjugated secondary antibody (Molecular Probes). For double immunofluorostaining, cytochrome $c$ - or mthsp70-stained cells were also incubated with Smac (sc-12684; Santa Cruz Biotechnology Inc.) and secondary antibody. Slides were mounted with Vectashield Mounting Medium with DAPI (H-1200; Vector Laboratories).

Isolation of mitochondrial fraction from A431 cells. Mitochondrial fractions were prepared following the protocol provided by the manufacturer (Compartmental Protein Extract Kit, 2145; Chemicon International).

Immunoprecipitation. The mitochondrial fraction $(200 \mu \mathrm{g}$ protein) prepared from A431 cells was incubated for 2 hours at $4{ }^{\circ} \mathrm{C}$ with anti-p53 (1 $\mu \mathrm{g}$, sc-6243; Santa Cruz Biotechnology Inc.) or anti-MnSOD (06-984; Upstate) followed by incubation with protein A-Sepharose for 1 hour at $4^{\circ} \mathrm{C}$. The immunoprecipitates were washed 5 times with cell lysis buffer (10 mM Tris pH 7.4, 1.0\% Triton X-100, 0.5\% NP-40, 150 mM NaCl, $20 \mathrm{mM}$ $\mathrm{NaF}, 0.2 \mathrm{mM}$ sodium orthovanadate, $1 \mathrm{mM}$ EDTA, $1 \mathrm{mM}$ EGTA, and 0.2 $\mathrm{mM}$ PMSF) and analyzed by Western immunoblotting.

\section{Tissue analyses}

Preparation of tissue lysate. Skin tissue samples were washed with ice-cold $1 \times$ PBS and homogenized in an ice-cold lysis buffer $(50 \mathrm{mM}$ HEPES, $150 \mathrm{mM}$ $\mathrm{NaCl}, 2.5 \mathrm{mM}$ EGTA, $1 \mathrm{mM}$ EDTA, $1 \mathrm{mM} \mathrm{NaF}, 0.1 \%$ Tween 20, 10\% glycerol, $10 \mathrm{mM} \beta$-glycerophosphate, $10 \mathrm{mM}$ DTT, $0.5 \mathrm{mM} \mathrm{Na}_{3} \mathrm{VO}_{4}$, and protease inhibitor, $\mathrm{pH}$ 8). This homogenate was then sonicated for 10 seconds twice on ice. Clear lysate was prepared by centrifugation at $10,000 \mathrm{~g}$ for 10 minutes. Extracts were aliquotted in small volumes and stored at $-80^{\circ} \mathrm{C}$ before use.

Immunohistochemical analyses of Bax and Bcl2. Formalin-fixed sections were embedded in paraffin and sectioned onto positively charged slides (Superfrost/Plus; Fisher Scientific). After deparaffinization and rehydration through xylene and graded alcohols, slides were placed in citric acid $(0.01 \mathrm{M})$ solution (Antigen Unmasking Solution; Vector Laboratories) and microwaved until boiling. After cooling, endogenous peroxidase activity was quenched with a 5 -minute incubation in a $3 \%$ hydrogen peroxide solution in water. The nonspecific sites were blocked in $2.5 \%$ normal serum for 1 hour followed by overnight incubation at $4{ }^{\circ} \mathrm{C}$ in primary antibody Bax and Bcl2. The sections were then washed and incubated with biotinylated secondary antibody. Color reaction was observed using the ABC Peroxidase Detection System (Vector Laboratories) with 3,3'-diaminobenzidine. Sections were counterstained with Harris hematoxylin (Sigma-Aldrich), dehydrated through alcohol and xylene, and mounted using Permount (Sigma-Aldrich).

Terminal deoxynucleotidyl transferase-mediated nick end labeling. TUNEL analysis was performed using a kit from Roche Applied Science (no. $1684795)$ according to the manufacturer's guidelines.

Statistics. Statistical analysis was performed using Microsoft Excel software. The significance between the 2 test groups was determined using Student's $t$ test. 


\section{Experimental design: studies in animals}

Experiment I: effects of CP-31398 on chronically UVB-irradiated mice. Eighteen SKH-1 mice were divided into 3 groups of 6 each. The group II and group III mice were irradiated with $180 \mathrm{~mJ} / \mathrm{cm}^{2} \mathrm{UVB}$ twice weekly for 16 weeks, whereas group I received no treatment and served as negative control. On the last day of treatment, beginning immediately following UVB irradiation, group III mice received CP-31398 treatment $(50 \mathrm{mg} / \mathrm{kg}$ body weight/ 12 h i.p.; 2 injections). Mice from all 3 groups were killed 24 hours following the last UVB exposure according to the recommendations of the Institutional Animal Care and Use Committee of Columbia University.

Experiment II: effects of CP-31398 on the growth of UVB-induced tumor. Eighteen SKH-1 mice were irradiated with UVB $\left(180 \mathrm{~mJ} / \mathrm{cm}^{2}\right.$ twice per week $)$ for 40 weeks. This irradiation induced skin tumors in $100 \%$ of irradiated mice. After 40 weeks, UVB irradiation was discontinued, and tumor-bearing animals were divided into 2 groups of 9 each in such a way that initially each group had approximately the same number of tumors. Group 1 animals were then given $0.9 \% \mathrm{NaCl}$ (i.p.) 5 times per week, whereas group 2 mice received $10 \mathrm{mg} / \mathrm{kg}$ body weight of $\mathrm{CP}-31398$ in $0.9 \% \mathrm{NaCl}$ (i.p.) 5 times per week for 4 weeks. Tumor number and tumor volume were recorded once a week and plotted in terms of weeks on test. In addition, we incorporated 10 age-matched mice, which received no treatments and served as negative controls. At the end of 44 weeks, the experiment was terminated and all the animals were killed. Their skin and tumors were harvested and processed for tissue lysate preparation for Western blot analysis as described in Western blotting.

Experiment III: chemoprevention study. In this study, we recruited $100 \mathrm{SKH}-1$ mice and divided them into 4 groups of 25 each. Group I received no treatment and served as negative age-matched controls. Groups II, III, and IV were irradiated with UVB $\left(180 \mathrm{~mJ} / \mathrm{cm}^{2}\right.$ twice per week $)$ for 35 weeks. Group II animals received no other treatment while groups III and IV received, respectively, topical application of vehicle (petrolatum) and CP-31398 $(1.25 \mathrm{mg} / 0.2 \mathrm{ml}$ petrolatum per application) 30 minutes prior to each UVB treatment. This formulation was developed and standardized in the Columbia University/New York Presbyterian Hospital Pharmacy. Following 35 weeks of treatments, the experiment was terminated by killing mice from all experimental and control groups.

Effects of CP-31398 on UVB-irradiated $p 53^{-1-/ S K H-1}$ mice. In this experiment, we recruited 9 each of $\mathrm{p} 53^{-/ /} / \mathrm{SKH}-1$ and $\mathrm{p} 53^{+/+} / \mathrm{SKH}-1$ littermates. Mice from these groups were divided into 3 groups, each consisting of 3 mice. Group I mice received topically applied vehicle for 3 days and served as negative controls. Group II and III mice were irradiated with $240 \mathrm{~mJ} / \mathrm{cm}^{2} \mathrm{UVB}$ every other day for 3 days. Group III mice also received a topical application of CP-31398 (1.25 mg/mouse/0.2 ml acetone/corn oil). Twenty-four hours after the last treatment, animals from all the groups were sacrificed.

\section{Experimental design: studies in cultured cells}

Effects of CP-31398 on cell-cycle regulation in A431 cells. In this experiment, we treated cells with various concentrations of CP-31398 $(0-40 \mu \mathrm{g} / \mathrm{ml})$ as indicated in the Figure 5 legend for different time intervals (0-24 hours). After these treatments, cells were harvested and either fixed for analyses on FACS or lysed for protein analyses on Western blot employing specific antibodies or total RNA extraction using TRIzoL reagent (15596-026; Invitrogen) for RT-PCR using specific primers: $21^{\text {WAF1/CIP1 }}$, forward 5'-GGGGGCATCATCAAAAACTT- ${ }^{\prime}$ and reverse $5^{\prime}$-ACTGAAGGGAAAGGACAAG- ${ }^{\prime}$; and for G3PDH, forward $5^{\prime}$-TCCCATCACCATCTTCCA- $3^{\prime}$ and reverse $5^{\prime}$-CATCACGCCACAGTTCC-3'.

Effects of CP-31398 on the induction of apoptosis in A431 cells. For studying the effects of CP-31398 on the induction of apoptosis in A431 cells, we treated cells grown on chamber slides for fluorescence-dependent apoptosis assays or for immunocytochemistry and in petri dishes for protein blotting with various concentrations of CP-31398 and for different time intervals, as indicated in legend for Figure 6. In this experiment, we used NHEKs as control, carrying wild-type p53. After these treatments, cells were stained as described earlier or lysed for protein analyses on Western blot employing specific antibodies.

Effects of CP-31398 on the alterations in mitochondrial membrane potential and on the release of mitochondrial proteins in A431 cells. For this experiment, we seeded $5 \times 10^{5}$ cells. Twenty-four hours after seeding, these cells were pretreated with cyclosporine $\mathrm{A}(1 \mu \mathrm{M})$ for 20 minutes and were treated with the various concentrations of CP-31398 (0-40 $\mu \mathrm{g} / \mathrm{ml})$ for $10 \mathrm{~min}$ utes. Then these cells were stained with JC-1 dye and analyzed on a FACS machine as described earlier.

Effects of CP-31398 on the targeting of activated $p 53$ to mitochondria in A431 cells. In this experiment, 15,000 cells seeded on a chamber slide for 24 hours were treated with CP-31398 as described earlier for apoptosis induction studies. Thereafter, these cells were stained with MitoTracker red and then fixed with $4 \%$ paraformaldehyde, permeabilized with $0.2 \%$ Triton X-100, and processed for immunofluorescent staining using p53 antibody as described under Fluorescent staining of $p 53$.

Effects of cyclosporine A on CP-31398-induced mitochondrial translocation of $p 53$, permeability pore transition, and apoptosis induction in A431 cells. In this experiment, 15,000 cells seeded on a chamber slide for 24 hours were treated with cyclosporine A and CP-31398 in the same succession as described earlier under Fluorescent staining of $p 53$ for mitochondrial membrane potential assessment. Thereafter, these cells were stained with MitoTracker (Figure 7, A, C, and E) and then fixed with $4 \%$ paraformaldehyde, permeabilized with $0.2 \%$ Triton $\mathrm{X}-100$, and processed for immunofluorescent staining using p53 or cytochrome $c$ antibody as described under Fluorescent staining of p53.

\section{Acknowledgments}

This work was supported in part by USPHS NIH grants R01 ES015323, NO1-CN-43300, N01-CN-35109, N01-CN-35105 (to M. Athar), K01 AR048582 (to A.L. Kim), R01 CA105136, and CA097249 (to D.R. Bickers). CP-31398 (lot 10960) was kindly provided by the NCI.

Received for publication April 23, 2007, and accepted in revised form September 19, 2007.

Address correspondence to: Mohammad Athar, Department of Dermatology, The University of Alabama at Birmingham, Volker Hall, Room 509, 1670 University Blvd., Birmingham, Alabama 35294-0019, USA. Phone: (205) 934-7554; Fax: (205) 934-7500; E-mail: mathar@uab.edu.
1. Vogelstein, B., and Kinzler, K.W. 2004. Cancer genes and the pathways they control. Nat. Med. 10:789-799.

2. Vogelstein, B., Lane, D., and Levine, A.J. 2000. Surfing the p53 network. Nature. 408:307-310.

3. van Kranen, H.J., and de Gruijl, F.R. 1999. Mutations in cancer genes of UV-induced skin tumors of hairless mice. J. Epidemiol. 9:S58-S65.

4. Phan, T.A., Halliday, G.M., Barnetson, R.S., and
Damian, D.L. 2006. Spectral and dose dependence of ultraviolet radiation-induced immunosuppression. Front. Biosci. 11:394-411.

5. D’Errico, M., Lemma, T., Calcagnile, A., Santis, L.P.D., and Dogliotti, E. 2007. Cell type and DNA damage specific response of human skin cells to environmental agents. Mutat. Res. 614:37-47.

6. Mitchell, D.L., and Nairn, R.S. 1989. The biology of the (6-4) photoproduct. Photochem. Photobiol.
49:805-819.

7. Ehrhart, J.C., Gosselet, F.P., Culerrier, R.M., and Sarasin, A. 2003. UVB-induced mutations in human key gatekeeper genes governing signalling pathways and consequences for skin tumourigenesis. Photochem. Photobiol. Sci. 2:825-834.

8. Giglia-Mari, G., and Sarasin, A. 2003. TP53 mutations in human skin cancers. Hum. Mutat. 21:217-228.

9. van Kranen, H.J., et al. 2005. Dose-dependent 
effects of UVB-induced skin carcinogenesis in hairless p53 knockout mice. Mutat. Res. 571:81-90.

10. Nelson, M.A., et al. 1994. Analysis of the p53 gene in human precancerous actinic keratosis lesions and squamous cell cancers. Cancer Lett. 85:23-29.

11. Cleaver, J.E., and Crowley, E. 2002. UV damage, DNA repair and skin carcinogenesis. Front. Biosci. 7:d1024-d1043.

12. Kim, A.L., et al. 1999. Conformational and molecular basis for induction of apoptosis by a p53 C-terminal peptide in human cancer cells. J. Biol. Chem. 274:34924-34931.

13. El-Deiry, W.S. 2001. Insights into cancer therapeutic design based on p53 and TRAIL receptor signaling. Cell Death Differ. 8:1066-1075.

14. el-Deiry, W.S. 1998. Regulation of p53 downstream genes. Semin. Cancer. Biol. 8:345-357.

15. Hupp, T.R., Sparks, A., and Lane, D.P. 1995. Small peptides activate the latent sequence-specific DNA binding function of p53. Cell. 83:237-245.

16. Roth, J.A., and Grammer, S.F. 2003. Tumor suppressor gene therapy. Methods Mol. Biol. 223:577-598.

17. Marx, J. 2007. Oncology. Recruiting the cell's own guardian for cancer therapy. Science. 315:1211-1213.

18. Blagosklonny, M.V. 2002. P53: an ubiquitous target of anticancer drugs. Int. J. Cancer. 98:161-166.

19. Foster, B.A., Coffey, H.A., Morin, M.J., and Rastinejad, F. 1999. Pharmacological rescue of mutant p53 conformation and function. Science. 286:2507-2510.

20. Wang, W., Takimoto, R., Rastinejad, F., and El-Deiry, W.S. 2003. Stabilization of p53 by CP-31398 inhibits ubiquitination without altering phosphorylation at serine 15 or 20 or MDM2 binding. Mol. Cell. Biol. 23:2171-2181

21. Wang, W., Kim, S.H., and El-Deiry, W.S. 2006. Small-molecule modulators of p53 family signaling and antitumor effects in p53-deficient human colon tumor xenografts. Proc. Natl. Acad. Sci. U. S. A. 103:11003-11008.

22. Wang, W., Rastinejad, F., and El-Deiry, W.S. 2003. Restoring p53-dependent tumor suppression. Cancer Biol. Ther. 2:S55-S63.

23. Bickers, D.R., and Athar, M. 2000. Novel approaches to chemoprevention of skin cancer. J. Dermatol. 27:691-695.

24. Starcher, B., and Conrad, M. 1995. A role for neutrophil elastase in solar elastosis. Ciba Found. Symp. 192:338-346; discussion 346-347.

25. Takimoto, R., and Niitsu, Y. 2004. Tumor suppressor gene p53 and molecular targeting therapy [In Japanese]. Gan To Kagaku Ryoho. 31:1309-1313.

26. Bykov, V.J., Selivanova, G., and Wiman, K.G. 2003. Small molecules that reactivate mutant p53. Eur.J. Cancer. 39:1828-1834.

27. Reiss, M., et al. 1992. Status of the p53 tumor suppressor gene in human squamous carcinoma cell lines. Oncol. Res. 4:349-357.

28. Park, D.J., et al. 1994. Transactivational and DNA binding abilities of endogenous p53 in p53 mutant cell lines. Oncogene. 9:1899-1906.
29. Ogawa, Y., et al. 2004. Reactive oxygen speciesproducing site in radiation-induced apoptosis of human peripheral T cells: involvement of lysosomal membrane destabilization. Int. J. Mol. Med. 13:69-73.

30. Smiley, S.T., et al. 1991. Intracellular heterogeneity in mitochondrial membrane potentials revealed by a J-aggregate-forming lipophilic cation JC-1. Proc. Natl. Acad. Sci. U. S. A. 88:3671-3675.

31 Reers, M., Smith, T.W., and Chen, L.B. 1991. J-aggregate formation of a carbocyanine as a quantitative fluorescent indicator of membrane potential. Biochemistry. 30:4480-4486.

32. Di Lisa, F., et al. 1995. Mitochondrial membrane potential in single living adult rat cardiac myocytes exposed to anoxia or metabolic inhibition. J. Physiol. 486:1-13.

33. Chaoui, D., et al. 2006. JC-1, a sensitive probe for a simultaneous detection of P-glycoprotein activity and apoptosis in leukemic cells. Cytometry B Clin. Cytom. 70:189-196.

34. Erster, S., Mihara, M., Kim, R.H., Petrenko, O., and Moll, U.M. 2004. In vivo mitochondrial p53 translocation triggers a rapid first wave of cell death in response to DNA damage that can precede p 53 target gene activation. Mol. Cell. Biol. 24:6728-6741.

35. Chipuk, J.E., and Green, D.R. 2006. Dissecting p53-dependent apoptosis. Cell Death Differ. 13:994-1002.

36. Chipuk, J.E., Maurer, U., Green, D.R., and Schuler, M. 2003. Pharmacologic activation of p53 elicits Bax-dependent apoptosis in the absence of transcription. Cancer Cell. 4:371-381.

37. Zhao, Y., et al. 2005. p53 translocation to mitochondria precedes its nuclear translocation and targets mitochondrial oxidative defense proteinmanganese superoxide dismutase. Cancer Res. 65:3745-3750.

38. Marques-Santos, L.F., Coqueiro, V.M., and Rumjanek, V.M. 2006. Cyclosporin A does not protect the disruption of the inner mitochondrial membrane potential induced by potassium ionophores in intact K562 cells. Cell Biol. Int. 30:197-204.

39. Tay, V.K., et al. 2005. Mitochondrial permeability transition as a source of superoxide anion induced by the nitroaromatic drug nimesulide in vitro. Free Radic. Biol. Med. 39:949-959.

40. Levine, A.J., Momand, J., and Finlay, C.A. 1991. The p53 tumour suppressor gene. Nature. 351:453-456.

41. Leng, R.P., et al. 2003. Pirh2, a p53-induced ubiquitin-protein ligase, promotes p53 degradation. Cell. 112:779-791.

42. Duan, W., et al. 2006. Differential response between the p53 ubiquitin-protein ligases Pirh2 and MdM2 following DNA damage in human cancer cells. Exp. Cell Res. 312:3370-3378

43. Kim, A.L., Athar, M., Bickers, D.R., and Gautier, J. 2002. Stage-specific alterations of cyclin expression during UVB-induced murine skin tumor development. Photochem. Photobiol. 75:58-67.
44. Kastan, M.B. 2007. Wild-type p53: tumors can't stand it. Cell. 128:837-840.

45. Ventura, A., et al. 2007. Restoration of p53 function leads to tumour regression in vivo. Nature. 445:661-665.

46. Xue, W., et al. 2007. Senescence and tumour clearance is triggered by p53 restoration in murine liver carcinomas. Nature. 445:656-660.

47. Bernal, F., Tyler, A.F., Korsmeyer, S.J., Walensky, L.D., and Verdine, G.L. 2007. Reactivation of the p53 tumor suppressor pathway by a stapled p53 peptide. J. Am. Chem. Soc. 129:2456-2457.

48. Bykov, V.J., et al. 2002. Restoration of the tumor suppressor function to mutant $\mathrm{p} 53$ by a low-molecular-weight compound. Nat. Med. 8:282-288.

49. Nahi, H., et al. 2004. Effects of PRIMA-1 on chronic lymphocytic leukaemia cells with and without hemizygous p53 deletion. Br. J. Haematol. 127:285-291.

50. Vassilev, L.T., et al. 2004. In vivo activation of the p53 pathway by small-molecule antagonists of MDM2. Science. 303:844-848.

51. Sausville, E.A., Burger, A.M., Becher, O.J., and Holland, E.C. 2006. Contributions of human tumor xenografts to anticancer drug development. Cancer Res. 66:3351-3354.

52. McDonald, E.R., 3rd, and El-Deiry, W.S. 2000. Cell cycle control as a basis for cancer drug development (review). Int. J. Oncol. 16:871-886.

53. Ho, C.K., and Li, G. 2005. Mutant p53 melanoma cell lines respond differently to CP-31398-induced apoptosis. Br. J. Dermatol. 153:900-910.

54. Luu, Y., Bush, J., Cheung, K.J., Jr., and Li, G. 2002. The p53 stabilizing compound CP-31398 induces apoptosis by activating the intrinsic Bax/ mitochondrial/caspase-9 pathway. Exp. Cell Res. 276:214-222.

55. Rippin, T.M., et al. 2002. Characterization of the p53-rescue drug CP-31398 in vitro and in living cells. Oncogene. 21:2119-2129.

56. Takimoto, R., et al. 2002. The mutant p53-conformation modifying drug, CP-31398, can induce apoptosis of human cancer cells and can stabilize wild-type $\mathrm{p} 53$ protein. Cancer Biol. Ther. 1:47-55

57. Wang, W., et al. 2005. Acridine derivatives activate p53 and induce tumor cell death through Bax. Cancer Biol. Ther. 4:893-898.

58. Wang, W., and El-Deiry, W.S. 2004. Targeting p53 by PTD-mediated transduction. Trends Biotechnol. 22:431-434.

59. Wischhusen, J., Naumann, U., Ohgaki, H., Rastinejad, F., and Weller, M. 2003. CP-31398, a novel p53-stabilizing agent, induces p53-dependent and p53-independent glioma cell death. Oncogene. 22:8233-8245.

60. Luo, J.L., et al. 2001. UV-induced DNA damage and mutations in Hupki (human p53 knock-in) mice recapitulate p53 hotspot alterations in sunexposed human skin. Cancer Res. 61:8158-8163.

61. Mihara, M., et al. 2003. p53 has a direct apoptogenic role at the mitochondria. Mol. Cell. 11:577-590. 